\title{
Dynamic Behavioral Analysis of Electrical Contacts in Engine Starter Solenoid using Ansys ${ }^{\circledR}$
}

\author{
Naik Nithesh $\dot{A}^{\dot{*}}$, Saba Khan $\stackrel{\dot{A}}{\text {, Swetha Gogineni }} \stackrel{\dot{A}}{\text {, Shweta Krishnan }}{ }^{\dot{A}}$, Suhas Kowshik ${ }^{\dot{A}}$ and Prajwal Shenoy $\dot{A}$ \\ ${ }^{\grave{A}}$ Mechanical and Manufacturing Engineering, Manipal Institute of Technology, Manipal University, Manipal, Karnataka, India
}

Accepted 10 January 2014, Available online 01 February 2014, Special Issue-2, (February 2014)

\begin{abstract}
In this paper an attempt has been made to analyze and simulate the dynamic behavior of electrical contacts in starter solenoid which causes phenomenon called Contact Bounce.A model based simulation and analysis of solenoid, based on a typical practical implementation has been carried out to predict accurately the contact bouncing characteristics considering all the nonlinear dynamic interaction of various springs and masses involved.The work included the study and evaluation modal and transient structural analysis of the solenoid using ANSYS so as to serve as reference, taking into consideration force developed on the plunger due to electromagnetic interactions, dynamics of various springs, masses and damper. Also simulation of the contact bounce of the existing solenoid is also carried out using ANSYS and LS- PrePost and frequency and magnitude of undesired behavior. i.e. Contact bounce is established.
\end{abstract}

Keywords: Contact Bounce, Solenoid, Transient structural analysis, Explicit dynamic analysis.

\section{Introduction}

Solenoid switch used in the starter motor performs mainly two functions, namely actuation of the plunger to actuate drive assembly of the starter motor thus facilitating engagement of pinion with ring gear and closure of switch contacts to enable transfer of electrical power to the starter motor. The mechanical system of the starter solenoid comprises of multiple spring mass system to achieve specific objectives.

Despite several research and advancements in solenoids, developing zero bounce energy efficient design continues to be an engineering challenge. With the increased competition in the automotive sector, everyone is looking forward to better performance machines, hence there arises a need to reduce or eliminate the contact bounce in the existing solenoid complying with all functional and cost constraints.

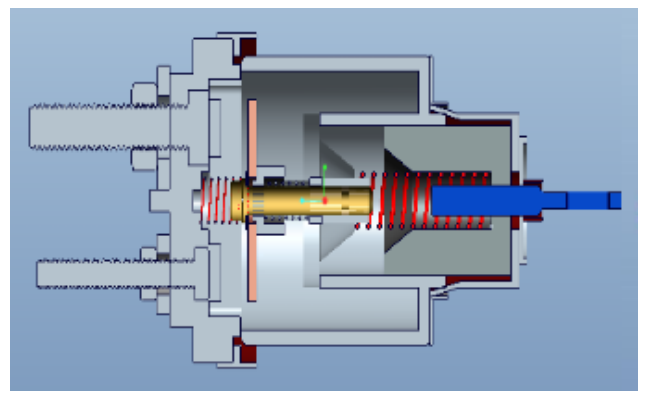

Fig 1 Cross sectional view of starter solenoid

*Corresponding author: Naik Nithesh

DOI: http://dx.doi.org/10.14741/ijcet/spl.2.2014.110
The invention (Freitas et al, 1996) provides a solenoid comprising a copper terminal stud having an integral first fixed contact, a steel terminal stud having an integral second fixed contact and a copper movable contact disposed in opposition to the first and second fixed contacts for switchable coupling the first and second fixed contacts as shown in Fig 1. The present invention provides a solenoid having a reduced cost over alternative designs while still providing superior performance.

A model was developed (Koba Yashi, 1999) which consists of an elastically deformable flat plate like elastic deformable portion having a contact portion which is contacted by the moving contact and a terminal bolt connected to a battery. When a movable contact moves with a plunger and contacts the fixed contact, movement energy upon contacting is absorbed and the movable contact is prevented from bouncing against the fixed contact because the fixed contact is elastically deformed when the movable contact is brought into contact with the fixed contact. This prevents abrasion of the movable and fixed contacts due to large current sparking. In addition because the movable contact and fixed contact directly contact each other, no voltage drop is produced thereby preventing degradation.

An electromagnetic switch (Takashi Hirobayashi) for a starter comprises a current supply terminal and a vibration absorber configured to absorb vibration imposed on the terminal. The terminal is provided so that one end of the terminal is tightly attached to the switch, and the other end is connected to a cable which supplies electric current to the switch. One end of the terminal is tightly attached to a 
bobbin wound by an excitation coil to which the current is supplied and the end protrudes through a molded cover outward to be connected to the cable at a connection port formed in the molded cover. The vibration absorber is a bent portion of the terminal formed integrally with the terminal itself. One or more flexible members are attached to the terminal to support it from within the electromagnetic switch and to seal inner spaces between the terminal and the switch.

\section{Mathematical Modeling}

Fig 2 shows free body diagram for starter solenoid. The following is an equation for a spring mass system with viscous damping,

$m \ddot{x}+C \dot{x}+k x=0$

The measured values for solenoid considered for evaluation is obtained experimentally as $\mathrm{m}=0.36 \mathrm{~g}$, $\mathrm{C}=100 \mathrm{~N} / \mathrm{s}, \mathrm{k}=367.8 \mathrm{~kg} / \mathrm{m}$

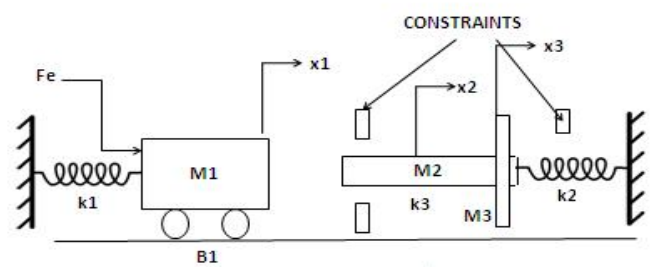

Fig 2 Free body diagram (FBD) of starter solenoid

Critically damping coefficient, $\mathrm{c}_{\mathrm{c}}=2 \sqrt{k / m}=0.733$

Damping Ratio $\zeta=\mathrm{c} / \mathrm{c}_{\mathrm{c}}=100 / 0.733>1$, Hence the system is over damped.

The natural frequency of the system is given by,

$\omega^{2}=\frac{k}{m} \quad \Rightarrow \omega=1010.77 \mathrm{rad} / \mathrm{s}$.

$\mathrm{f}_{\mathrm{n}}=\frac{1}{2 \pi} \sqrt{\frac{k}{m}}=160.87 \mathrm{~Hz}$

\section{Meshing}

The tetrahedron mesh which is a type of patch conforming method mesh (Fig 3) was found to give suitable results for modal static structural and transient structural analysis. When this mesh was used in explicit dynamics it gave errors and hence the simple mapped mesh with an element size of $0.003 \mathrm{~m}$ was used.

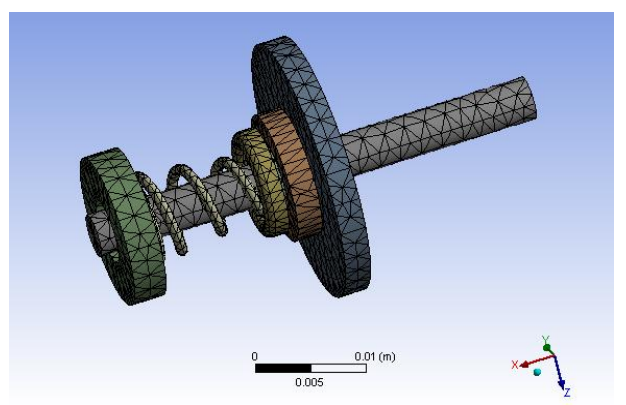

Fig 3 Patch Conforming Method- Tetrahedron Mesh

\section{Hardness measurement test}

In order to find the appropriate material of each component the Vickers hardness number was measured using the hardness testing machine. From the hardness number obtained the relevant material was selected and its properties were obtained and the same is been incorporated in ANSYS workbench 14.0 during simulation. The hardness number and material are shown in Table 1.

Table1 Material Hardness

\begin{tabular}{|l|l|l|l|}
\hline S. No. & Components of Solenoid & $\begin{array}{l}\text { Vickers's } \\
\text { Hardness } \\
\text { Number }\end{array}$ & Material \\
\hline 1. & Moving Contact & 94.1 & Cu Alloy \\
\hline 2. & Damper & 40 & Plastic \\
\hline 3. & Washer & 192 & Brass \\
\hline 4. & Tapered Spring & 444.3 & Steel \\
\hline 5. & Lock Plate & 460.8 & Grey CI \\
\hline 6. & Spindle & 234.5 & Brass \\
\hline
\end{tabular}

\section{Material Properties}

Table2 Material Properties

\begin{tabular}{|l|l|l|l|l|}
\hline Material & $\begin{array}{l}\text { Young's } \\
\text { Modulus } \\
(\mathrm{Pa})\end{array}$ & $\begin{array}{l}\text { Poison } \\
\text { Ratio }\end{array}$ & $\begin{array}{l}\text { Bulk Modulus } \\
(\mathrm{Pa})\end{array}$ & $\begin{array}{l}\text { Density } \\
\mathrm{kg} \mathrm{m}^{\wedge}-3\end{array}$ \\
\hline $\begin{array}{l}\text { Structural } \\
\text { Steel }\end{array}$ & $2 . \mathrm{e}+011$ & 0.3 & $1.6667 \mathrm{e}+011$ & 7850 \\
\hline Stainless Steel & $1.93 \mathrm{e}+011$ & 0.31 & $1.693 \mathrm{e}+011$ & 7750 \\
\hline Copper Alloy & $1.1 \mathrm{e}+011$ & 0.34 & $1.1458 \mathrm{e}+011$ & 8300 \\
\hline Polyethylene & $1.1 \mathrm{e}+009$ & 0.42 & $2.2917 \mathrm{e}+009$ & 950 \\
\hline $\begin{array}{l}\text { Gray Cast } \\
\text { Iron }\end{array}$ & $7.1 \mathrm{e}+010$ & 0.334 & $7.1285 \mathrm{e}+010$ & 7200 \\
\hline
\end{tabular}

\section{Modal Analysis}

Modal analysis is performed in order to find out the natural frequency and compare it with theoretical results obtained. On solving, the frequencies were obtained for 10 modes (Table 3) and the first mode corresponded to the natural frequency mode for vibration in the $\mathrm{X}$ direction.

Table 3 Modal frequencies

\begin{tabular}{|l|l|}
\hline Mode & Frequency $[\mathrm{Hz}]$ \\
\hline 1. & 153.84 \\
\hline 2. & 592.98 \\
\hline 3. & 689.55 \\
\hline 4. & 3024. \\
\hline 5. & 3244.7 \\
\hline 6. & 3858.7 \\
\hline 7. & 4144.3 \\
\hline 8. & 5212.3 \\
\hline 9. & 5886.5 \\
\hline 10. & 6851.7 \\
\hline
\end{tabular}

The experimental result thus obtained for the $\mathrm{X}$ direction natural frequency is $153.84 \mathrm{~Hz}$ and the theoretical result 
for the same is $160.87 \mathrm{~Hz}$. The result obtained is well within the error limits $( \pm 5 \%)$. Fig 5 , Fig 6 , Fig 7, Fig 8,Fig 9, Fig 10, Fig 11, Fig 12, and Fig 13 shows deformation of system at various modal frequencies.

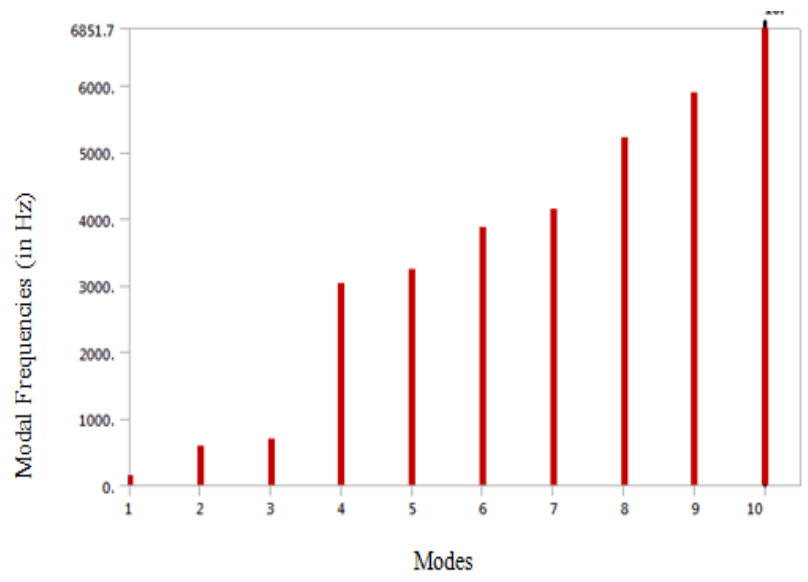

Fig 4 Graph of modal frequencies versus modes

The Fig 4 indicates the frequency at each calculated mode. The first modal frequency obtained was $153.84 \mathrm{~Hz}$ which resulted in deformation in $\mathrm{X}$ direction. The deformations at other modes were either bending or torsional.

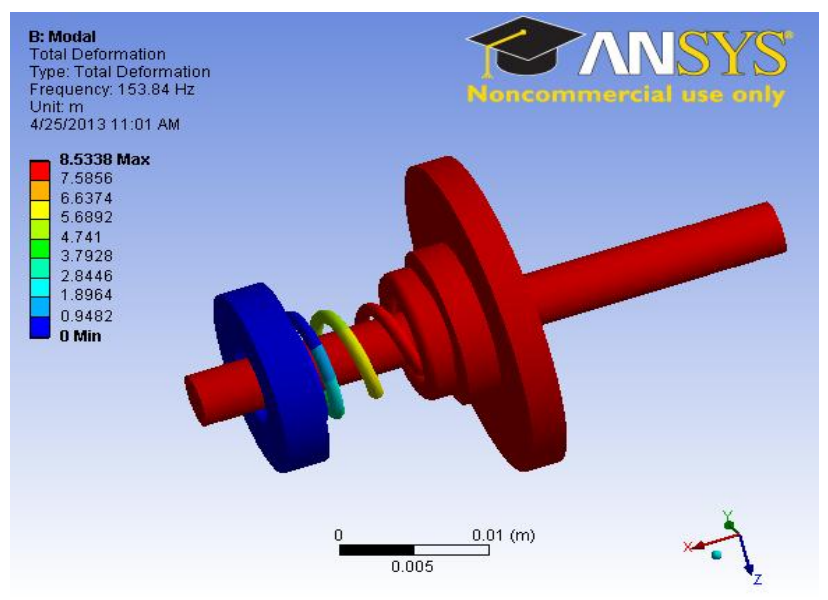

Fig 5 Total deformation for Mode 1

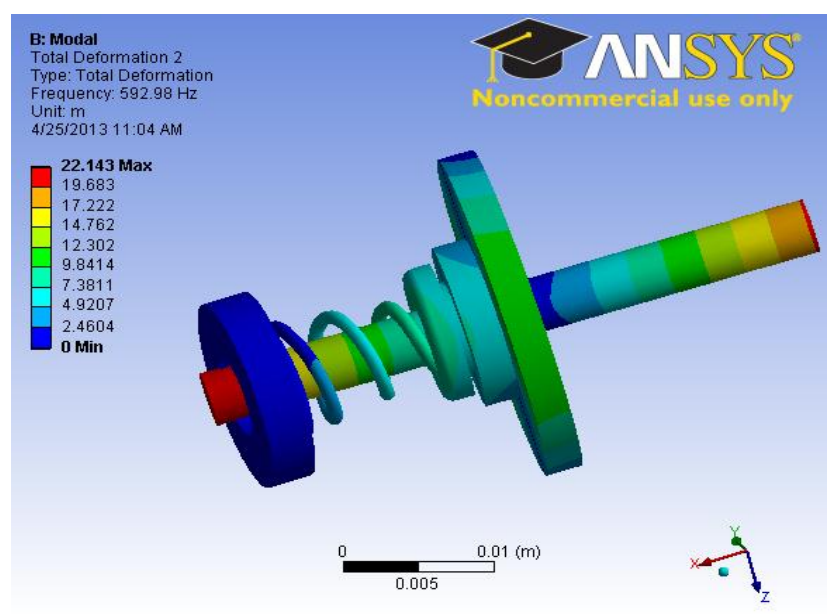

Fig 6 Total deformation for Mode 2

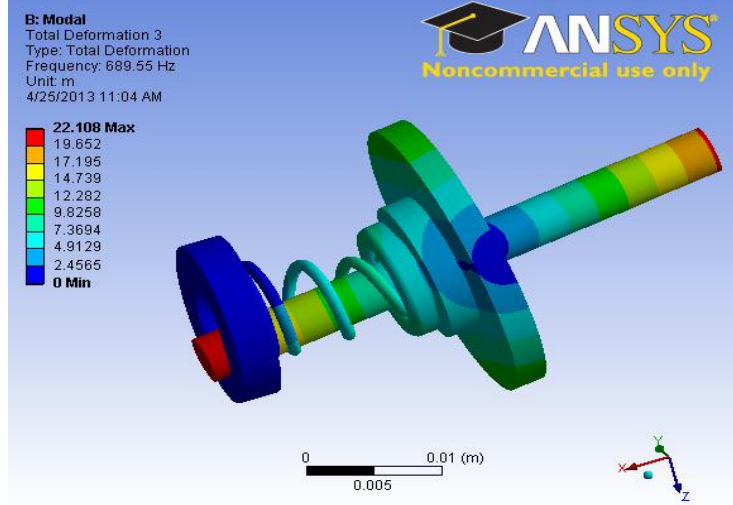

Fig 7 Total deformation for Mode 3

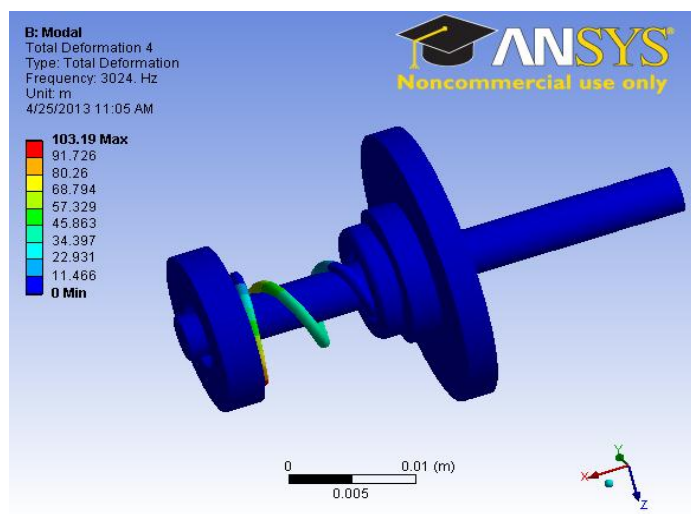

Fig 8 Total deformation for Mode 4

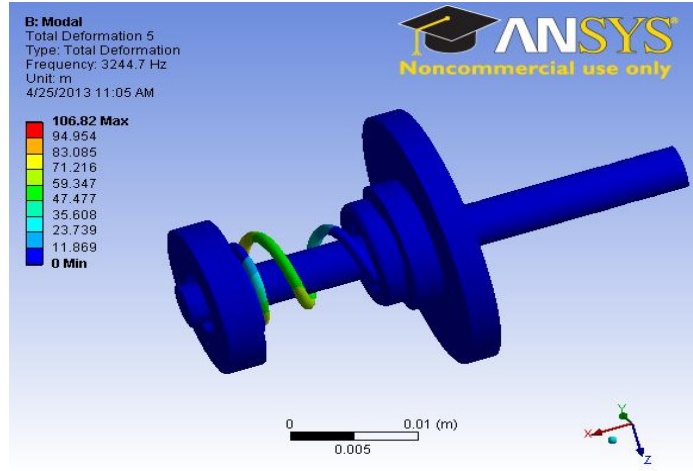

Fig 9 Total deformation for Mode 5

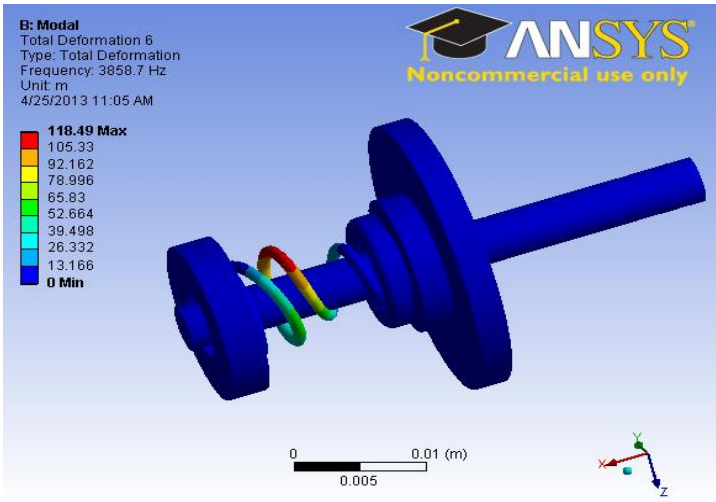

Fig 10 Total deformation for Mode 6 


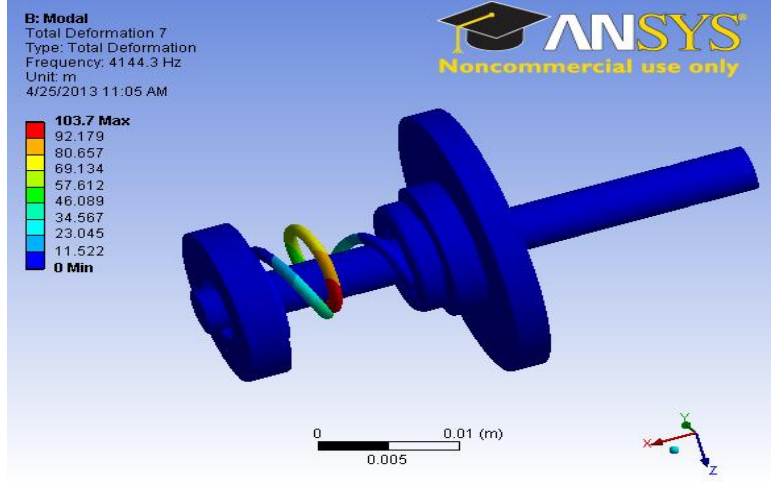

Fig 11 Total deformation for Mode 7

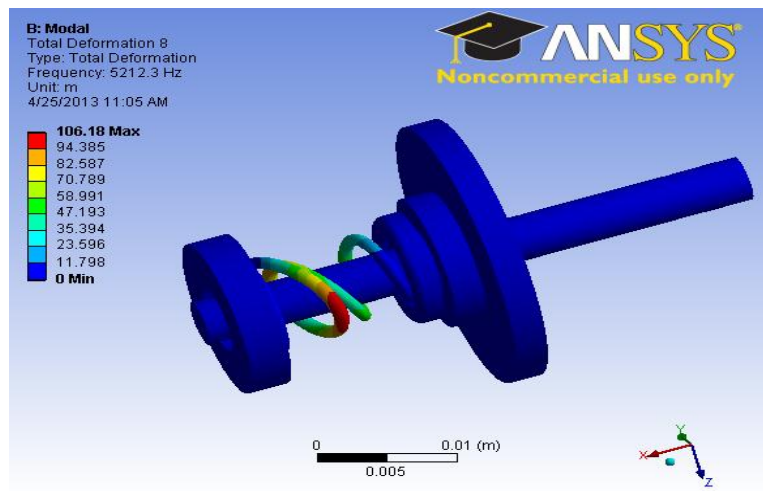

Fig 11 Total deformation for Mode 8

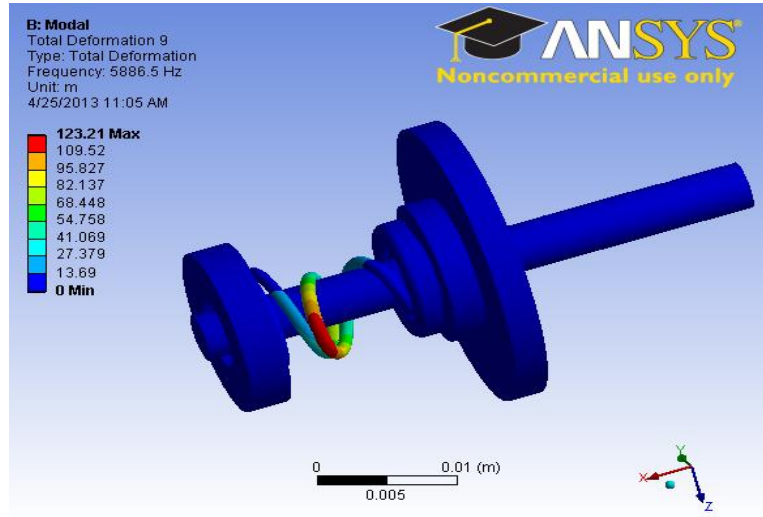

Fig 12 Total deformation for Mode 9

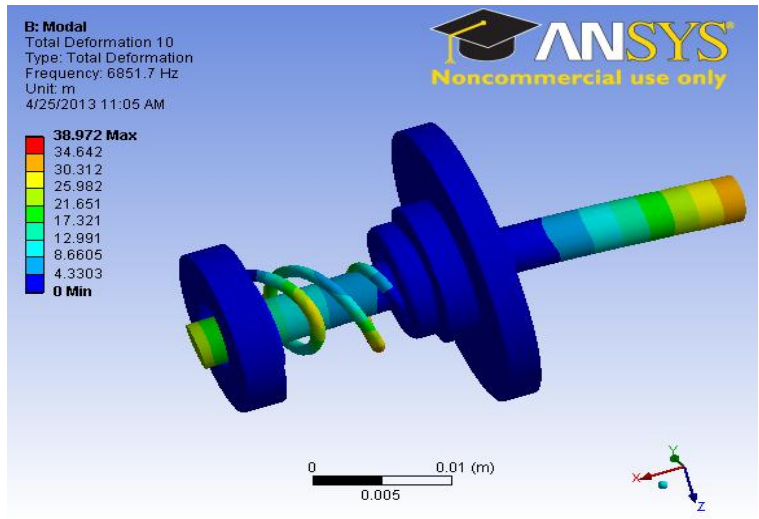

Fig13 Total deformation for Mode 10

\section{Static Structural Analysis}

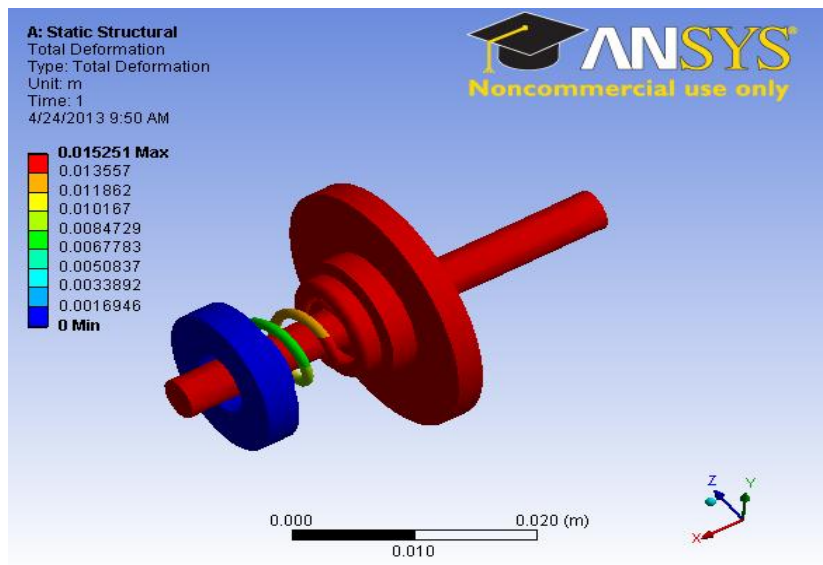

Fig 14 Total deformation- Static Structural

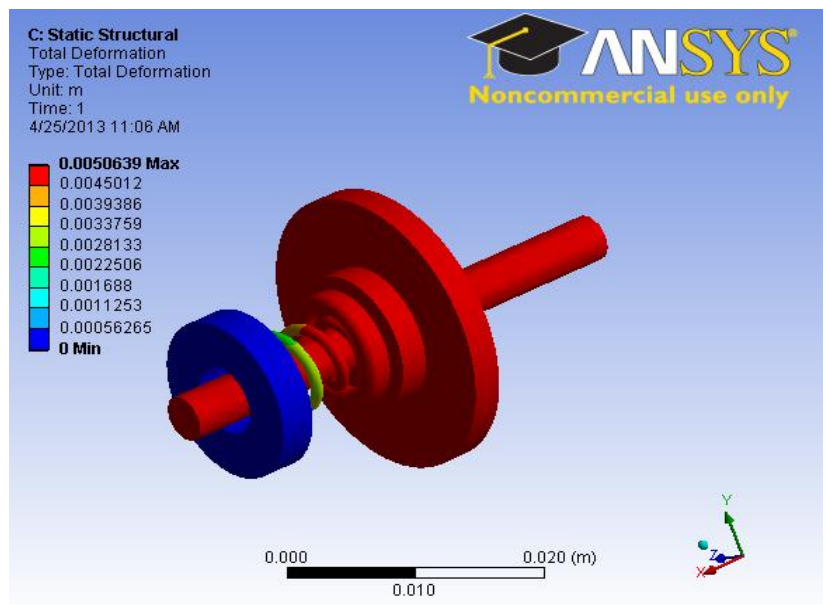

Fig 15 Total deformation- Static Structural with displacement

The static structural analysis was performed in order to incorporate the force acting on the moving contact as a constraint. Firstly, a simple analysis was carried out to see the deflection of the moving contact in the absence of the fixed contact. This resulted in a maximum deflection of $15.25 \mathrm{~mm}$ (Fig 14). Further improving the result, a displacement constraint of $5 \mathrm{~mm}$ (Fig 15) was added to the moving contact in order to accommodate the presence of fixed contact. Finally, the fixed contact was added to the geometry at a distance of $5 \mathrm{~mm}$ from the moving contact. Through this analysis, the moving contact touched the fixed contact. However, the force applied was constant throughout the analysis.

\section{Transient Analysis}

The transient structural analysis was performed to include time varying loads and displacements. An impact force of $200 \mathrm{~N}$ was given to the moving contact between 0 to $0.001 \mathrm{~s}$. The end time of the analysis was specified as $0.01 \mathrm{~s}$ and it was divided into 10 time steps which were further divided into 2 sub-steps each.The results obtained were in 
par with the requirement in which moving contact came in contact with the fixed contact on application of impact force (Fig 16).

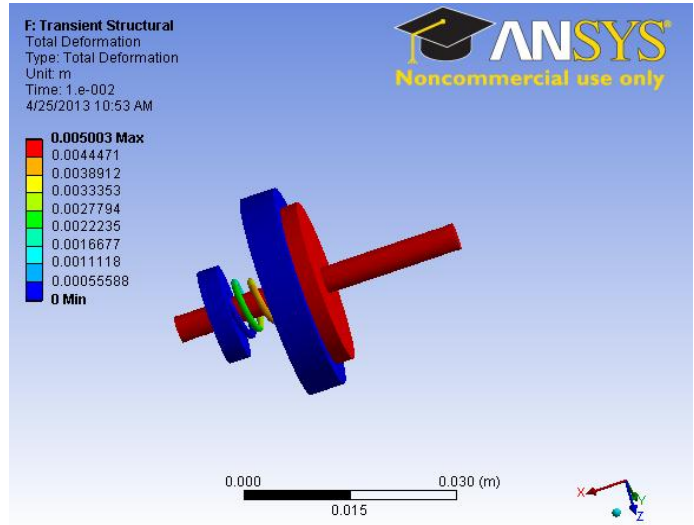

Fig 16 Total deformation- Transient Structural.

The Table 4 shows the results of deformation with respect to time and the (Fig 17) shows the plot of resultant deformation of the structure.

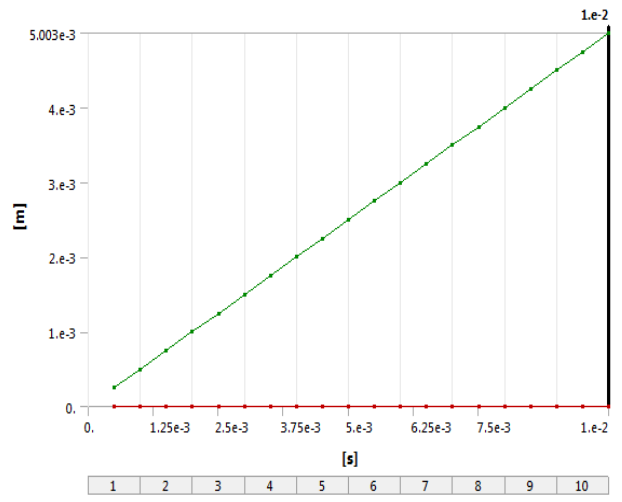

Fig 17 Graph of resultant deformation versus time

Table 4 Results of deformation w.r.t time

\begin{tabular}{|c|c|c|}
\hline Time [s] & Minimum [m] & Maximum [m] \\
\hline $5 . e-004$ & \multirow{20}{*}{0} & $2.5009 \mathrm{e}-004$ \\
\hline 1.e-003 & & $5.0018 \mathrm{e}-004$ \\
\hline $1.5 \mathrm{e}-003$ & & $7.5026 \mathrm{e}-004$ \\
\hline 2.e-003 & & $1.0004 \mathrm{e}-003$ \\
\hline $2.5 \mathrm{e}-003$ & & $1.2504 \mathrm{e}-003$ \\
\hline 3.e-003 & & $1.5005 \mathrm{e}-003$ \\
\hline $3.5 e-003$ & & $1.7506 \mathrm{e}-003$ \\
\hline 4.e-003 & & $2.0007 \mathrm{e}-003$ \\
\hline $4.5 \mathrm{e}-003$ & & $2.2508 \mathrm{e}-003$ \\
\hline 5.e-003 & & $2.5009 \mathrm{e}-003$ \\
\hline $5.5 e-003$ & & $2.7511 \mathrm{e}-003$ \\
\hline 6.e-003 & & $3.0012 \mathrm{e}-003$ \\
\hline $6.5 \mathrm{e}-003$ & & $3.2514 \mathrm{e}-003$ \\
\hline 7.e-003 & & $3.5015 \mathrm{e}-003$ \\
\hline $7.5 e-003$ & & $3.7517 \mathrm{e}-003$ \\
\hline 8.e-003 & & $4.002 \mathrm{e}-003$ \\
\hline $8.5 e-003$ & & $4.2522 \mathrm{e}-003$ \\
\hline 9.e-003 & & $4.5024 \mathrm{e}-003$ \\
\hline $9.5 \mathrm{e}-003$ & & $4.7527 \mathrm{e}-003$ \\
\hline 1.e-002 & & $5.003 \mathrm{e}-003$ \\
\hline
\end{tabular}

\section{Explicit Dynamic Analysis}

In ANSYS Explicit Dynamics (LS-DYNA Export) system all the constraints pertaining to the model were specified. The contacts between the various parts were removed and made automatic single surface for accurate results. The end time of the process was indicated at $0.01 \mathrm{~s}$. On solving in ANSYS Workbench 14.0, the LS-DYNA .k file format was created in a specified working directory.

Furthermore, this .k file was used for analysis and was terminated in product launcher to obtain a $\mathrm{d} 3$ plot. This solution file was opened using LS-Pre-Post to view the animated result and graphs were plotted. The plot of Energy with respect to time is obtained as shown in Fig 18. The animation included a successful simulation of the phenomenon of contact bounce.

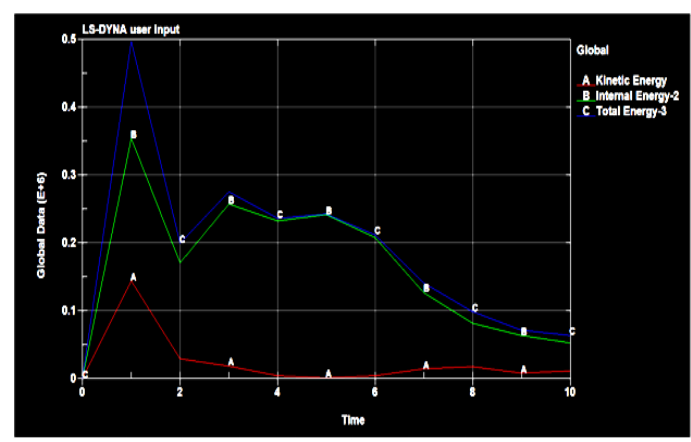

Fig 18 Graph of Energy versus Time

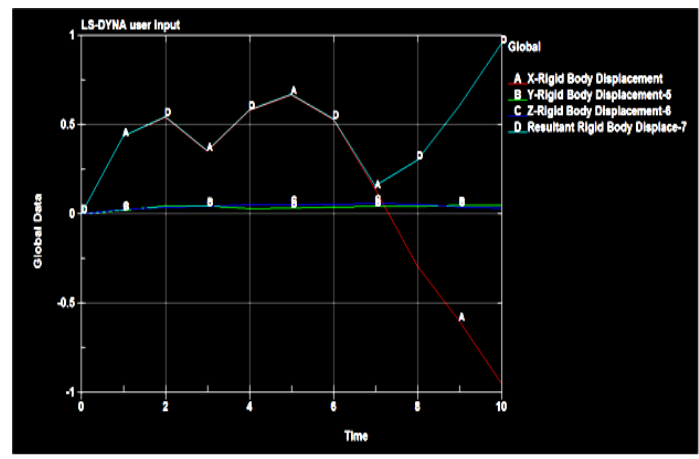

Fig 19 Graph of Displacement versus Time

The Fig 19 shows the variation in displacement of rigid body in the structure with respect to time.

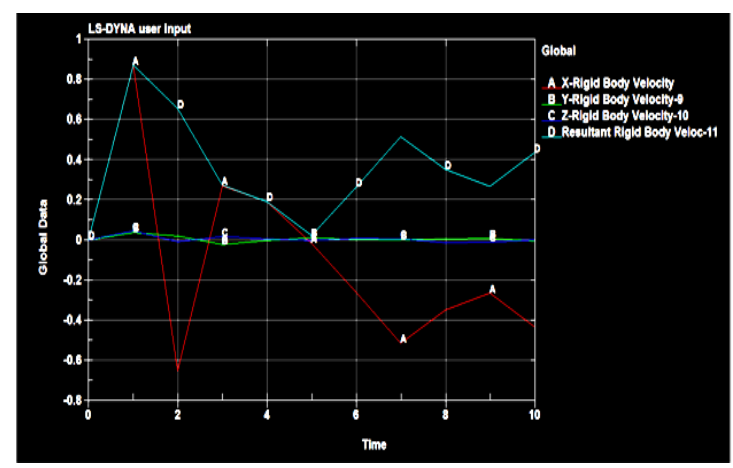

Fig 20 Graph of Velocity versus Time. 
The Fig 20 shows the variation in velocity of rigid body in the structure with respect to time.

\section{Conclusion}

The following conclusion can be drawn from the investigations,

The computation showed that simulations carried out using the methodology developed co-relates with the available contact bounce characteristics of solenoid taken into consideration for investigation.

A generalized model based simulation methodology built by feeding in the measured values of the parameters by mathematical formulation and ANSYS model simulates and replicates the contact bouncing characteristics.

The results indicate that the methodology adopted helps in understanding the characteristics of existing solenoids.

The deformation obtained in the static structural analysis was at par with the requirement as shown in Fig 14 and Fig 15.

The first modal frequency obtained in the modal analysis (Fig 5) was $153.85 \mathrm{~Hz}$ which is well within the error of $\pm 5 \%$ of the theoretical frequency of $160.87 \mathrm{~Hz}$. Transient structural analysis (Fig 16) shows the variation of deflection with respect to time.

From the results obtained by conducting computer simulations shows the phenomenon of contact bounce. The contact bounce was simulated using the LS- Dyna solver in ANSYS workbench and the result was viewed in LS-PrePost.

\section{References}

Robert E Prouty and James J Smith, (November, 1974) Electromagnetic solenoid with improved contact anti bounces means US Patent - 3848206, Essex International, Wayne

Charles M. Freitas, Massicotte and Xiaolin B, (October, 1996) Solenoid with an improved contact design and a system utilizing the solenoid US Patent - 5563563, Ford Motor Company, Dearborn

Kazuo Masaki, (September, 2006) Solenoid switch having moving contact configured to have moving contact to prevent contact bounce US Patent - 7504916 B2, Denso Corporation, Kariya.

Kobayashi and Shiga, (April, 1999) Magnet switches for starter with elastically deformable contact US Patent - 5894256, Denso Corporation, Kariya.

Hirabayashi, (June, 2006) Electromagnetic switch for starter US Patent - 0132268 A1, Denso Corporation, Kariya

Vaughan, N.D and Gamble(1996) The modeling and simulation of a proportional solenoid valve, Transactions of the ASME, vol. 118 (pages 120-125).

Cheung, N.C Lim and Rahman (1993) Modeling a Linear and Limited Travel solenoid. IEEE: 19th International Conference of on Industrial Electronics.

Y. Wang and A. Stefanopoulou (2002) Modeling and Control of Electromechanical Valve Actuator SAE Paper 2002-01-1106

Janusz Zeiba,(June, 2003) Simulation of Solenoid Actuator for a device for investigating dynamic air permeability through flat textile products, Technical University of Lodz, Department of Automation of Textile products, Poland, Vol 11, No. (2)

C. Rajalingam and S. Rakheja, (2000) Analysis of Impact Force during Collision of Two bodies using SDOF system model, Journal of Sound and Vibration 229(4). 